\title{
Deoxyactein protects pancreatic $\beta$-cells against methylglyoxal-induced oxidative cell damage by the upregulation of mitochondrial biogenesis
}

\author{
KWANG SIK SUH ${ }^{1 *}$, EUN MI CHOI $^{2 *}$, WOON-WON JUNG ${ }^{3}$, YU JIN KIM ${ }^{4}$, SOO MIN HONG ${ }^{4}$, \\ SO YONG PARK ${ }^{4}$, SANG YOUL RHEE $^{2}$ and SUK CHON ${ }^{2}$
}

\begin{abstract}
${ }^{1}$ Research Institute of Endocrinology, Kyung Hee University Hospital; ${ }^{2}$ Department of Endocrinology and Metabolism, School of Medicine, Kyung Hee University, Seoul 130-702; ${ }^{3}$ Department of Biomedical Laboratory Science, College of Health Sciences, Cheongju University, Cheongju, Chungbuk 360-764; ${ }^{4}$ Department of Medicine, Graduate School, Kyung Hee University, Seoul 130-702, Republic of Korea
\end{abstract}

Received December 14, 2015; Accepted June 2, 2017

DOI: $10.3892 / \mathrm{ijmm} .2017 .3018$

\begin{abstract}
Methylglyoxal (MG) is one of the major precursors of advanced glycation end products (AGEs), which are considered to be one of the causes of diabetes and its complications. The root and rhizomes of black cohosh (Cimicifuga racemosa) have long been used medicinally, and deoxyactein is one of its major constituents. In the present study, the protective effects of deoxyactein against MG-induced oxidative cell damage were investigated in insulin-producing pancreatic $\beta$-cells. We found that deoxyactein protected the pancreatic $\beta$-cells against MG-induced cell death. Pre-treatment with deoxyactein significantly reduced the levels of intracellular reactive oxygen species (ROS), interleukin-1 $\beta$ (IL-1 $\beta$ ), cardiolipin peroxidation, and protein adduct accumulation induced by MG. Pre-treatment of the cells with deoxyactein restored glyoxalase I activity and insulin secretion which were reduced by MG, and increased the mRNA expression of insulin 2 (INS2) and pancreatic and duodenal homeobox protein-1 (PDX-1). It also increased the levels of endogenous antioxidant enzymes, including superoxide dismutase (SOD) and glutathione peroxidase (GPX). Furthermore, treatment with deoxyactein increased the levels of sirtuin 1 (SIRT1) and peroxisome proliferator-activated receptor- $\gamma$ co-activator- $1 \alpha$ (PGC-1 $\alpha$ ). These findings indicate that deoxyactein may exert beneficial effects on pancreatic $\beta$-cells via the upregulation of mitochondrial biogenesis. Taken together, these results suggest that deoxyactein may be used for the prevention of pancreatic $\beta$-cell damage.
\end{abstract}

Correspondence to: Dr Suk Chon, Department of Endocrinology and Metabolism, School of Medicine, Kyung Hee University, 1 Hoegi-dong, Dongdaemun-gu, Seoul 130-702, Republic of Korea E-mail: imdrjs@khu.ac.kr

*Contributed equally

Key words: deoxyactein, methylglyoxal, oxidative stress, pancreatic $\beta$-cells, mitochondrial biogenesis

\section{Introduction}

Diabetes is a metabolic disorder characterized by hyperglycemia caused by pancreatic $\beta$-cells failing to produce sufficient amounts of insulin to meet the body's needs, or receptor insensitivity to endogenous insulin (1). Persistent hyperglycemia can lead to the accumulation of methylglyoxal (MG), a reactive dicarbonyl species, which has been implicated in various diabetic complications (2).

MG is a highly reactive dicarbonyl metabolite produced during glucose metabolism and is a major precursor of advanced glycated end products (AGEs), which are involved in the pathogenesis of diabetes and inflammation (3). It has been suggested that AGEs and MG can generate pro-inflammatory cytokines through the activation of receptor for AGE (RAGE), and that this is related to the modulation of inflammatory molecules through oxidative stress (3). AGEs also decrease insulin synthesis in pancreatic $\beta$-cells by repressing the protein expression of pancreatic duodenal homeobox-1 (PDX-1), which plays a significant role in both pancreatic development and the maintenance of $\beta$-cell functions (4). Under physiological conditions, MG is degraded into D-lactate by the glyoxalase system (5).

Glucotoxicity-induced oxidative stress is one of many classic risk factors (6), and damages the function of pancreatic islets and reduces insulin secretion via the overproduction of reactive oxygen species (ROS) (7). It has been suggested that oxidative stress plays a key role in the onset of type 2 diabetes (8). In addition, pancreatic $\beta$-cells express low physiological levels of antioxidant enzymes, such as superoxide dismutase (SOD), catalase (CAT) and glutathione peroxidase (GPX) $(9,10)$. Therefore, the maintenance of pancreatic $\beta$-cell function and preventing expanding cell mass represent the most feasible therapeutic strategies to control hyperglycemia in pathophysiological states of nutrient excess $(11,12)$.

Insulin is used in the treatment of type 1 diabetes, and many oral hypoglycemic agents are used in the treatment of type 2 diabetes (13). Due to their adverse side-effects and alleviation of symptoms while not targeting the cause, there have been persistent efforts to identify compounds that could potentially 
cure diabetes, for example by stimulating $\beta$-cell regeneration and preventing apoptosis, leading to a return of the endogenous control of glucose homeostasis. Studies on supplementation with natural products have demonstrated effects of reducing the hyperglycemic status by preserving the functions of pancreatic $\beta$-cells $(14,15)$. Naturally occurring plant compounds are attractive candidates as they are abundantly found in nature, inexpensive to produce, and may have fewer side-effects than currently used pharmaceutical compounds. Flavonoids have been shown to regulate carbohydrate digestion, insulin secretion, insulin signaling and glucose uptake in insulin-sensitive tissues through various intracellular signaling pathways (16). Flavonoids exert their effects by influencing pancreatic $\beta$-cell mass and function, as well as energy metabolism and insulin sensitivity in peripheral tissues. The anti-diabetic effects of flavonoids may be due to antioxidant, enzyme inhibitory, or receptor agonist or antagonist activity, or due to novel mechanisms which have yet to be elucidated (17).

Black cohosh (Cimicifuga racemosa) has a long history of medicinal use dating back to Native North American indigenous groups (18). It is used to reduce the frequency and intensity of hot flashes and it has been reported that there is an improvement in psychological complaints among users (18). To date, $>20$ of these triterpene glycosides have been isolated from this plant, of which 23-epi-26-deoxyactein (27-deoxyactein) is one of the major constituents.

In our previous studies, we reported that deoxyactein isolated from black cohosh promoted the function of osteoblastic MC3T3-E1 cells and reduced antimycin A-induced cell damage by preventing mitochondrial dysfunction and oxidative stress $(19,20)$. Model studies using RIN-m5F cells, a lineage of pancreatic $\beta$-cells, challenged with MG (21) and hydrogen peroxide (22), have begun to shed some light on the molecular mechanisms implicated in MG- and hydrogen peroxide-induced cytotoxicity. Given the mounting evidence for a major role of pancreatic $\beta$-cells in the pathogenesis of type 2 diabetes, in this study, we investigated the effects of deoxyactein on the MG-induced oxidative cell damage of pancreatic $\beta$-cells and the underlying mechanisms.

\section{Materials and methods}

Reagents. Deoxyactein, isolated from black cohosh (Cimicifuga racemosa), was purchased from ChromaDex Inc. (Irvine, CA, USA). This was dissolved in dimethyl sulfoxide (DMSO) and then diluted with culture medium [final DMSO concentration $\leq 0.05 \%(\mathrm{v} / \mathrm{v})]$. $\alpha$-modified minimal essential medium ( $\alpha$-MEM) and fetal bovine serum (FBS) were purchased from Gibco-BRL (Grand Island, NY, USA). Other reagents were purchased from Sigma Chemical (St. Louis, MO, USA).

Cell culture. RIN-m5F cells derived from rat pancreatic $\beta$-cells were purchased from the American Type Culture Collection (ATCC, Manassas, VA, USA). RIN-m5F cells were maintained in RPMI-1640 supplemented with 10\% FBS and $1 \%$ penicillin/streptomycin solution under conditions of saturated humidity in an atmosphere containing $5 \% \mathrm{CO}_{2}$ at $37^{\circ} \mathrm{C}$. The medium was renewed every 3 days. Forty-eight hours after seeding, the cells were pre-incubated for $1 \mathrm{~h}$ in medium containing $0.1 \%$ FBS and deoxyactein $(0.01-10 \mathrm{mM})$ prior to exposure to MG (30-500 $\mathrm{mM}$ ) for $48 \mathrm{~h}$. Aminoguanidine (AG, $400 \mu \mathrm{M})$, a carbonyl scavenger, was used as a positive control in our experiments.

Cell viability. The cells were seeded in 24-well culture plates at a density of $2 \times 10^{4}$ cells/well. After $48 \mathrm{~h}$ of seeding, the cells were incubated for $1 \mathrm{~h}$ with deoxyactein prior to treatment with MG for $48 \mathrm{~h}$. Cell viability was assessed by the 3-(4,5-dimethylthiazol2-yl)-2,5-diphenyltetrazolium bromide (MTT)method. A total of $20 \mu \mathrm{l}$ of MTT in phosphate-buffered salt solution, $\mathrm{pH} 7.4(5 \mathrm{mg} /$ $\mathrm{ml}$ ), was added to each well, and the plates were incubated for an additional $2 \mathrm{~h}$. After the removal of solution from the well, DMSO was added to dissolve the formazan products, and the plates were shaken for $5 \mathrm{~min}$. The absorbance was measured with a Zenyth 3100 multimode detector (Anthos Labtec Instruments, Wals/Salzburg, Austria) at $570 \mathrm{~nm}$. The cells incubated with culture medium alone were used to define $100 \%$ viability and were included as a control in all experiments to allow for the estimation of the percentage viability of the cell samples.

Measurements of insulin secretion. The cells were seeded in 24-well culture plates at a density of $2 \times 10^{4}$ cells/well. The culture conditions were the same as those described for the cell viability assay. Supernatants were collected for the measurement of secreted insulin using a high-range rat insulin enzyme-linked immunosorbent assay (ELISA) kit (Mercodia Inc., Uppsala, Sweden) according to the manufacturer's instructions. Protein concentrations were determined using Bio-Rad protein assay reagent.

RNA isolation and reverse transcription-quantitative PCR (RT-qPCR). The cells were seeded in 100-mm culture dishes at a density of $5 \times 10^{5}$ cells/dish. The culture conditions were the same as those described for the cell viability assay. Total RNA was extracted from each well of RIN-m5F cells using an RNeasy mini kit (Qiagen NV, Venlo, The Netherlands), and complementary DNA (cDNA) was synthesized using a PrimeScript First Strand DNA Synthesis kit (Takara Biotech, Otsu, Japan) according to the manufacturer's instructions. Quantitative PCR (qPCR) was performed using a SYBR Premix ExTaq kit (Takara Biotech, Dalian, China) and the ABI Prism 7500 sequence detection system (Applied Biosystems, Foster City, CA, USA) to determine the gene expression levels. Each PCR reaction was performed in a $20 \mu \mathrm{l}$ solution containing $0.8 \mu \mathrm{l}(10 \mu \mathrm{M})$ of each pair of forward and reverse primers, $10 \mu 1$ of Premix Ex Taq DNA polymerase, $0.4 \mu \mathrm{l}$ of ROX reference dye, $6 \mu \mathrm{l}$ of $\mathrm{dH}_{2} \mathrm{O}$, and $2 \mu \mathrm{l}$ of reverse transcription reaction products. The qRT-PCR primers used in the experiment are lissted in Table I. All experiments were performed in quadruplicate. Relative expression was determined using the $2^{-\Delta \Delta \mathrm{Cq}}$ method using the housekeeping gene, glucose 6-phosphate dehydrogenase (G6PD), as the internal control, and the fold change was calculated in comparison with the corresponding control group.

Measurement of interleukin (IL)-1 $\beta$ levels. The cells were seeded in a 24 -well plate at a density of $2 \times 10^{4}$ cells/well in culture medium. After $48 \mathrm{~h}$, the cells were exposed to deoxyactein or AG prior to exposure to $300 \mu \mathrm{M} \mathrm{MG}$ for $48 \mathrm{~h}$. Cellular IL-1 $\beta$ contents were measured using an enzyme 
Table I. Primer sequences used in this study.

\begin{tabular}{llcl}
\hline Gene & Accession no. & Forward primer & Reverse primer \\
\hline Insulin-2 & NM_019130.2 & 5'-CGA AGT GGA GGA CCC ACA-3' & 5'-TGC TGG TGC AGC ACT GAT-3' \\
PDX-1 & NM_022852.3 & 5'-ACC CGT ACA GCC TAC ACT CG-3' & 5'-GCC GGG AGA TGT ATT TGT TAA A-3' \\
SOD1 & NM_017050.1 & 5'-TAA GAA ACA TGGCGGTCC A-3' & 5'-TGG ACA CAT TGG CCA CAC-3' \\
GPX1 & NM_030826.3 & 5'-AGA AGG CTC ACC CGC TCT-3' & 5'-GGA TCG TCA CTG GGT GCT-3' \\
G6PD & NM_017006.2 & 5'-TGC AGC AGC TGT CCT CTA TG-3' & 5'-ACT TCA GCT TTG CGC TCA TT-3'
\end{tabular}

PDX-1, pancreatic and duodenal homeobox protein-1; SOD1, superoxide dismutase 1; GPX1, glutathione peroxidase 1; G6PD, glucose 6-phosphate dehydrogenase.

immunoassay system (R\&D Systems Inc., Minneapolis, MN, USA) according to the manufacturer's instructions. In brief, IL-6 present was bound by immobilized antibody precoated onto a microplate. After washing away any unbound substances, an enzyme linked polyclonal antibody specific for IL-1 $\beta$ was added to the well. Following a wash to remove any unbound antibody-enzyme reagent, a substrate solution was added to the wells. The enzyme reaction yielded a blue product that turned yellow when stop solution was added. The intensity of the color measured was in proportion to the amount of IL-1 $\beta$ bound. Cellular IL-1 $\beta$ contents were measured using an enzyme immunoassay system (R\&D Systems Inc.) according to the manufacturer's instructions.

Measurement of intracellular ROS levels. The cells were seeded in 24-well culture plates at a density of $2 \times 10^{4}$ cells/ well. The culture conditions were the same as those described for the cell viability assay. Formation of intracellular ROS was measured using 2',7'-dichlorodihydrofluorescin diacetate $\left(\mathrm{H}_{2} \mathrm{DCFDA}\right)$ (23). Viable cells can deacetylate $\mathrm{H}_{2} \mathrm{DCFDA}$ to the non-fluorescent derivative, $2^{\prime}, 7^{\prime}$-dichlorofluorescin (DCF), which reacts with oxygen species and can be measured to provide an index of intracellular oxidant production. In order to load the cells with the fluorescent dye, the cells were incubated with $\mathrm{H}_{2}$ DCFDA (Sigma Chemical) in Hank's solution at a final concentration of $10 \mu \mathrm{M}$ for $45 \mathrm{~min}$ at $37^{\circ} \mathrm{C}$ in the dark. Following washing with DPBS, the fluorescence intensity was measured (excitation $485 \mathrm{~nm}$, emission $515 \mathrm{~nm}$ ) using a Zenyth 3100 multimode detector (Anthos Labtec Instruments).

Measurement of cardiolipin peroxidation. The cells were seeded in 24-well culture plates at a density of $2 \times 10^{4}$ cells/well. The culture conditions were the same as those described for the cell viability assay. 10-N-nonyl-acridine orange (NAO; Molecular Probes, Inc., Eugene, OR, USA), which binds to mitochondrial cardiolipin, was used for the measurement of cardiolipin. Decreases in the fluorescence of NAO in cells reflect the peroxidation of intracellular cardiolipin as the fluorochrome loses its affinity for peroxidised cardiolipin. The cells were labeled with $5 \mu \mathrm{M}$ NAO for $20 \mathrm{~min}$. After washing, fluorescence was measured at an excitation wavelength of $485 \mathrm{~nm}$ and an emission wavelength of $530 \mathrm{~nm}$ using a Zenyth 3100 multimode detector.

Measurementofphosphorylated sirtuin 1(SIRT1) andperoxisome proliferator-activated receptor- $\gamma$ co-activator-1 $\alpha(P G C-1 \alpha)$.
The cells were seeded in 24-well culture plates at a density of $2 \times 10^{4}$ cells/well. The culture conditions were the same as those described for the cell viability assay. The cells were rinsed in ice-cold DPBS and homogenized in DPBS with a glass Dounce homogenizer (Taylor Scientific, USA) on ice. The resulting suspension was subjected to two freeze-thaw cycles to further break the cell membranes. Cell homogenates were centrifuged at $13,000 \mathrm{x} \mathrm{g}$ for $15 \mathrm{~min}$ at $4^{\circ} \mathrm{C}$ and the supernatant was used for ELISA and protein content measurement. SIRT1 was measured using a Sirtuin 1 ELISA kit (Cloud-Clone, Houston, TX, USA). PGC-1 $\alpha$ was measured using a mouse peroxisome proliferator activated receptor- $\gamma$ coactivator- $1 \alpha$ (PGC- $1 \alpha)$ ELISA kit (MyBioSource, San Diego, CA, USA). The kits were used according to the manufacturers' instructions.

Quantification of MG-modified proteins (adducts). The quantification of MG-modified proteins (MG-protein adducts) was determined using an ELISA kit purchased from Cell BioLabs, Inc. (San Diego, CA, USA). The MG protein adducts present in the sample or standard were probed with an anti-MG specific monoclonal antibody, followed by a horseradish peroxidase (HRP) conjugated secondary antibody (both contained in the ELISA kit, cat. no. STA-811). The quantity of MG adducts in the protein samples was determined by comparing their absorbances with that of a known MG-BSA standard curve.

Glyoxalase I activity. The cells were rinsed in ice-cold DPBS and homogenized them in DPBS with a glass Dounce homogenizer (Taylor Scientific) on ice. The resulting suspension was subjected to two freeze-thaw cycles to further break the cell membranes. Cell homogenates were centrifuged at 13,000 x g for $15 \mathrm{~min}$ at $4^{\circ} \mathrm{C}$ and the supernatant was used for glyoxalase I activity assay and protein content measurement. Glyoxalase I activity was measured using a modification of a previously published method (24). To measure glyoxalase I activity, $50 \mu \mathrm{l}$ of sample was loaded onto a UV microplate (Microtiter; Thermo Fisher Scientific, Waltham, MA, USA) and $200 \mu \mathrm{l}$ of reaction mix were added. The reaction mix consisted of $60 \mathrm{~mm}$ sodium phosphate buffer, $\mathrm{pH} 6.6$, containing $4 \mathrm{~mm}$ GSH and $4 \mathrm{~mm} \mathrm{MG}$, and was pre-incubated for $10 \mathrm{~min}$ at $37^{\circ} \mathrm{C}$. S-Lactoylglutathione synthesis was followed by the measurement of the absorbance at $240 \mathrm{~nm}$ for $5 \mathrm{~min}$ at $25^{\circ} \mathrm{C}$.

Statistical analysis. The results are expressed as the means \pm SEM. Statistical significance was determined by 

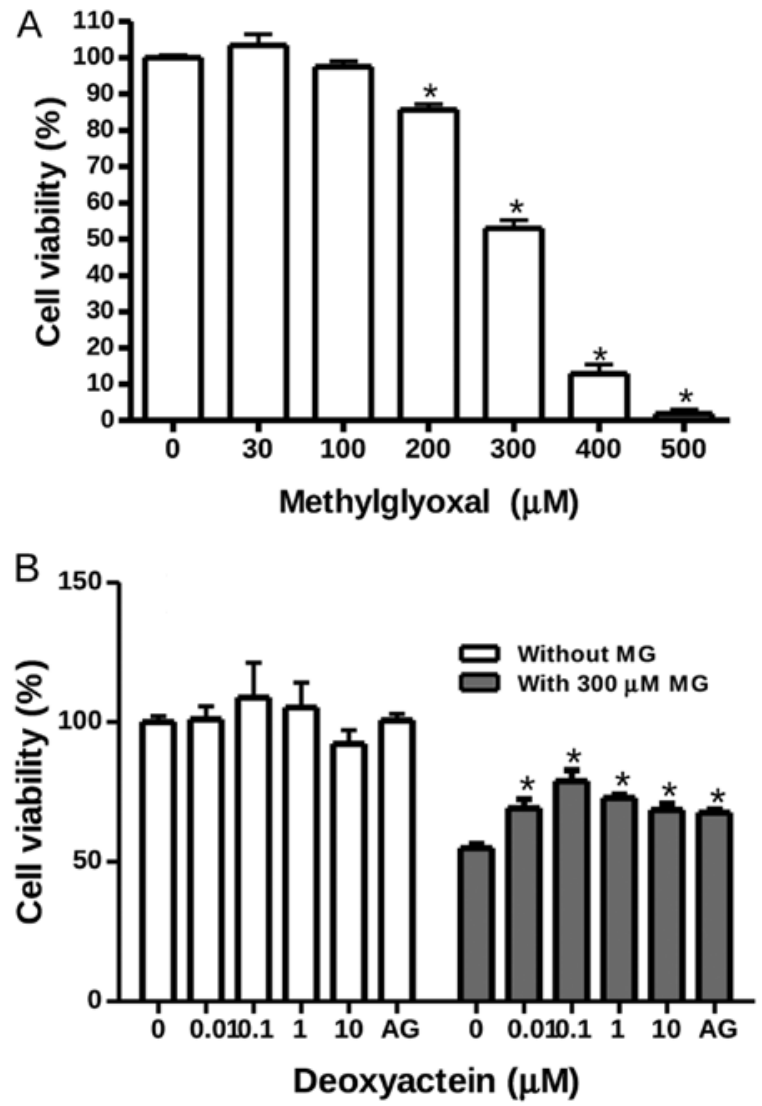

Figure 1. Effect of methylglyoxal (MG) and/or deoxyactein (DA) on the viability of RIN-m5F cells. (A) The cells were exposed to various concentrations of MG and cell viability was assessed by MTT assay. (B) The RIN-m5F cells were treated with DA or $400 \mu \mathrm{M}$ aminoguanidine (AG) in the absence or presence of $300 \mu \mathrm{M}$ MG for $48 \mathrm{~h}$, and cell viability was then assessed by MTT assay. Data are expressed as a percentage of the control group levels. " $\mathrm{P}<0.05$ compared with the controls.

analysis of variance and subsequently applying Dunnett's t-test. A value of $\mathrm{P}<0.05$ was considered to indicate a statistically significant difference.

\section{Results}

Effects of deoxyactein on the viability of RIN-m5F cells. RIN-m5F cells were exposed to MG at concentrations ranging from 30 to $500 \mu \mathrm{M}$ for $48 \mathrm{~h}$. Thereafter, cell viability was measured by MTT assay. Our results revealed that MG at concentrations of $\leq 100 \mu \mathrm{M}$ had no effect on the viability of RIN-m5F cells; however, it decreased their viability at concentrations of $\geq 200 \mu \mathrm{M}$. At $300 \mu \mathrm{M}, \mathrm{MG}$ decreased cell viability by $\sim 50 \%$ (Fig. 1A). To determine whether deoxyactein exerts a protective effect against MG-induced cytotoxicity, the cells were pre-incubated with deoxyactein for $1 \mathrm{~h}$ and then cultured with $300 \mu \mathrm{M}$ MG for $48 \mathrm{~h}$. Deoxyactein at concentrations of $\leq 10 \mu \mathrm{M}$ had no effect on the viability of RIN-m5F cells in the absence of MG (Fig. 1B). However, pre-treatment with deoxyactein (0.01-10 $\mu \mathrm{M})$ inhibited MG-induced cytotoxicity significantly. AG $(400 \mu \mathrm{M})$, a carbonyl scavenger, also inhibited the cytotoxicity induced by MG.

Deoxyactein relieves $M G$-abrogated insulin secretion and increases the gene expression of INS2 and PDX-1. Insulin secre-
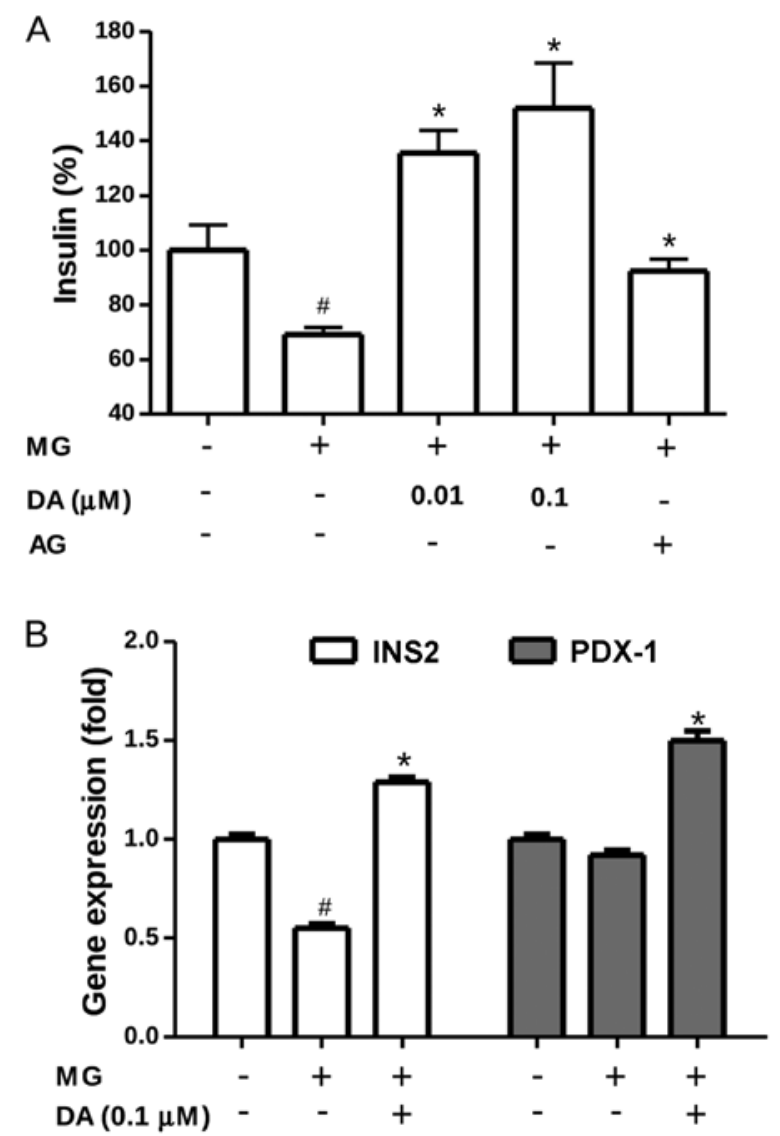

Figure 2. Effect of deoxyactein (DA) on insulin secretion and related gene expression in methylglyoxal (MG)-exposed cells. The RIN-m5F cells were incubated with DA or $400 \mu \mathrm{M}$ aminoguanidine (AG) prior to exposure to $300 \mu \mathrm{M}$ MG for $48 \mathrm{~h}$. (A) Insulin secretion was then measured using an ELISA kit. (B) Gene expression was measured by RT-qPCR. " $\mathrm{P}<0.05$ compared with untreated cells; ${ }^{*} \mathrm{P}<0.05$ compared with cells exposed to $\mathrm{MG}(300 \mu \mathrm{M})$ alone.

tion was evaluated in order to examine the protective effects of deoxyactein on $\beta$-cell functionality. Exposure to $300 \mu \mathrm{M}$ MG resulted in a marked decrease in insulin secretion by the RIN-m5F cells (Fig. 2A), indicating a stress-induced loss of insulin functionality. Most interestingly, insulin secretion by the RIN-m5F cells exposed to MG was completely restored when these cells were pre-treated with deoxyactein $(0.01-0.1 \mu \mathrm{M})$ or AG. These results indicated that deoxyactein preserved not only RIN-m5F cell viability, but also the most important $\beta$-cell function, insulin secretion. Alterations in insulin signal transduction can lead to $\beta$-cell dysfunction, contributing to the pathogenesis of type 2 diabetes (25). Thus, to investigate whether deoxyactein modulates the expression profile of different genes important for $\beta$-cell functioning, we compared the gene expression levels of a series of regulators of insulin secretion processes in pancreatic $\beta$-cells. As shown in Fig. $2 \mathrm{~B}$, the results of RT-qPCR revealed that MG significantly downregulated the transcription level of the INS2 gene compred to that in the control cells $(\mathrm{P}<0.05)$. Pre-treatment with $0.1 \mu \mathrm{M}$ deoxyactein significantly mitigated the decrease in the gene expression of INS2 induced by exposure to MG. In addition deoxyactein increased the expression of PDX1 in the cells.

Deoxyactein decreases the production of $I L-1 \beta$ in $M G$-exposed $R I N-m 5 F$ cells. MG promotes the formation of pro-inflam- 


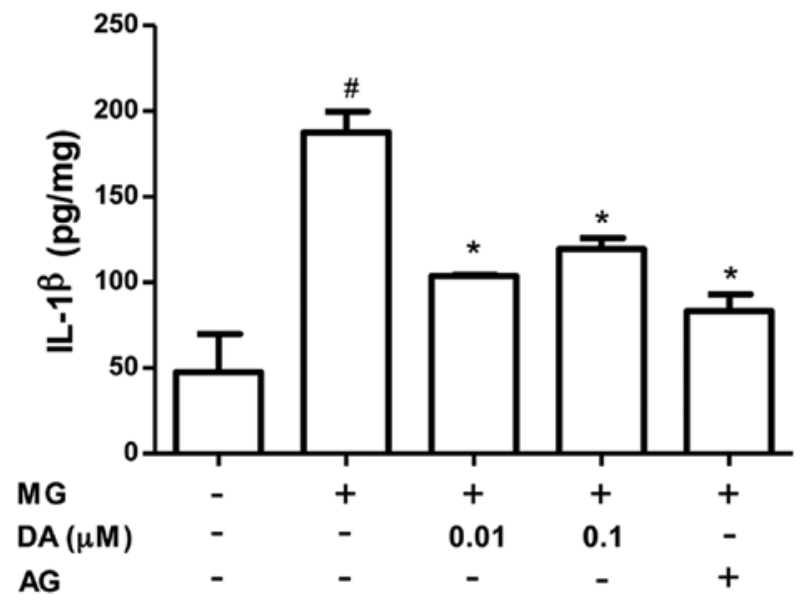

Figure 3. Effect of deoxyactein (DA) on the levels of interleukin-1 $\beta$ (IL-1 $\beta$ ) in methylglyoxal (MG)-exposed cells. The RIN-m5F cells were incubated with DA or $400 \mu \mathrm{M}$ aminoguanidine (AG) prior to exposure to $300 \mu \mathrm{M} \mathrm{MG}$ for $48 \mathrm{~h}$. The control value for IL-1 $\beta$ was $47.61 \pm 22.32 \mathrm{pg} / \mathrm{mg}$. ${ }^{~} \mathrm{P}<0.05$ compared with untreated cells; ${ }^{*} \mathrm{P}<0.05$ compared with cells exposed to $\mathrm{MG}(300 \mu \mathrm{M})$ alone.

matory cytokines in various cell types (26-28). Thus, we also investigated whether deoxyactein modulates the production of IL-1 $\beta$ in MG-exposed cells (Fig. 3). When $300 \mu \mathrm{M}$ MG was added to the cell medium, the production of IL-1 $\beta$ increased significantly. However, the MG-induced production of IL-1 $\beta$ was significantly inhibited by pre-treatment with deoxyactein at concentrations of 0.01-0.1 $\mu \mathrm{M}$. AG also decreased the MG-induced production of IL-1 $\beta$.

Deoxyactein decreases ROS production and increases the gene expression of SOD and GPX in MG-exposed cells. Intracellular ROS levels were measured using the oxidation-sensitive probe, DCFH-DA. As shown in Fig. 4A, exposure to $300 \mu \mathrm{M}$ MG significantly increased the ROS levels compared with those in the control cells $(\mathrm{P}<0.05)$. Under conditions of MG toxicity, deoxyactein $(0.1 \mu \mathrm{M})$ or AG suppressed the increase of ROS significantly $(\mathrm{P}<0.05)$, suggesting that the cytoprotective effects of deoxyactein are partly attributable to its regulation of ROS production. To obtain furtherevidence for oxidative stress within the mitochondria, we assessed the oxidation of cardiolipin, as this phospholipid exists in association with cytochrome $c$ on the outer surface of the inner mitochondrial membrane (29). As the fluorescent dye, NAO, binds to the non-oxidized form, but not to the oxidized form of cardiolipin, measurements of NAO fluorescence allow us to monitor the oxidation of cardiolipin in the mitochondria (30). The results revealed that exposure to $300 \mu \mathrm{M}$ MG decreased NAO fluorescence, indicating the induction of cardiolipin peroxidation (Fig. 4B). However, deoxyactein $(0.1 \mu \mathrm{M})$ or $\mathrm{AG}$ reduced cardiolipin peroxidation induced by MG. These data indicated that deoxyactein reduced MG-induced ROS generation and oxidative stress within the mitochondria. The effects of deoxyactein on the expression of the SOD and GPX genes in the RIN-M5F $\beta$-cells were also examined. As shown in Fig. 4C, the mRNA expression level of SOD decreased in the RIN-M5F $\beta$-cells exposed to MG cells compared to that in the control cells. However, pre-treatment with deoxyactein $(0.1 \mu \mathrm{M})$ significantly mitigated the decreased gene expression of SOD observed in the
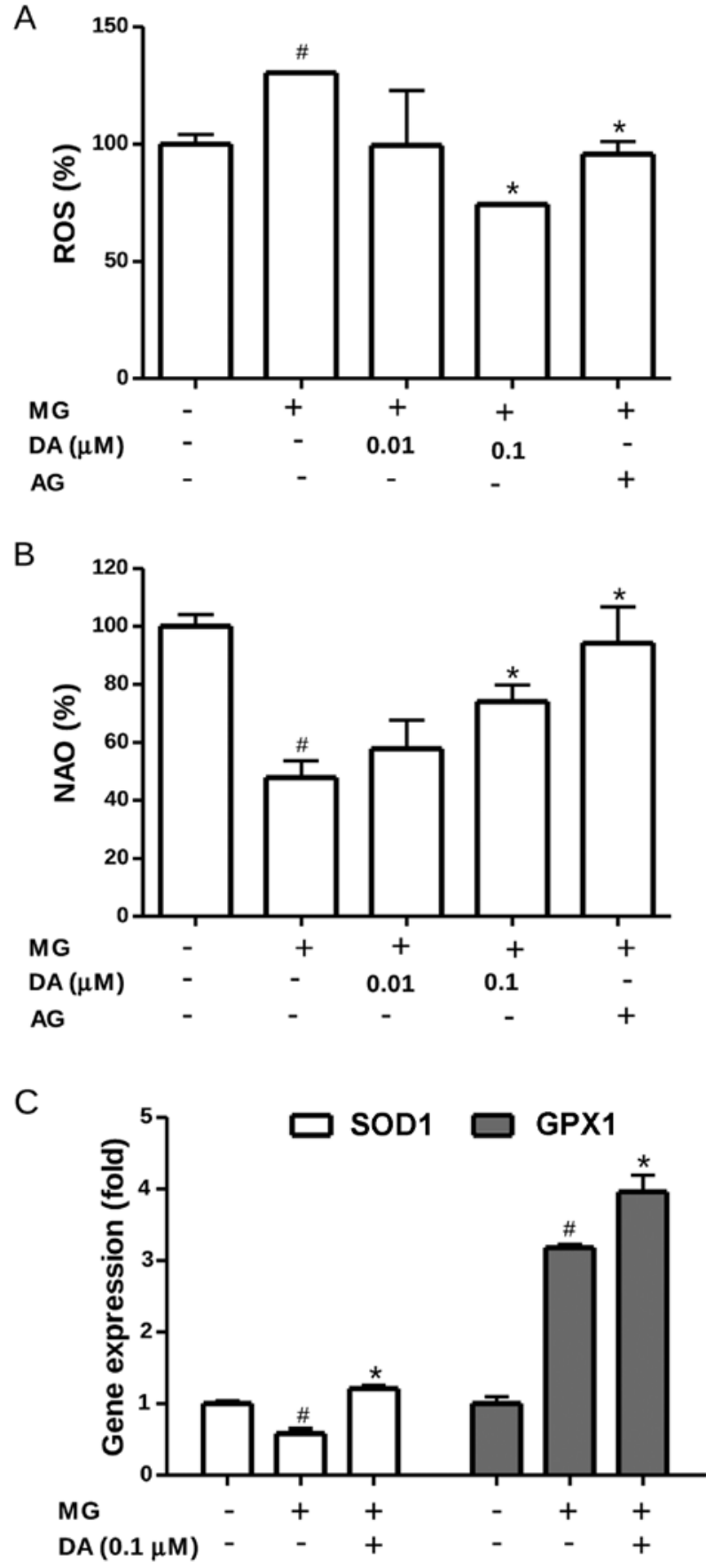

Figure 4. Effect of deoxyactein (DA) on oxidative stress and antioxidant enzyme expression in methylglyoxal (MG)-exposed cells. The RIN-m5F cells were incubated with DA or $400 \mu \mathrm{M}$ aminoguanidine (AG) prior to exposure to $300 \mu \mathrm{M}$ MG for $48 \mathrm{~h}$. (A) The generation of reactive oxygen species (ROS) was measured using the oxidation-sensitive probe, DCFH-DA. (B) Cardiolipin peroxidation was determined by $10-\mathrm{N}$-nonyl-acridine orange (NAO) fluorescence. Note that MG exposure led to a decrease in NAO binding, which is related to cardiolipin peroxidation. (C) The expression of the antioxidant genes, superoxide dismutase 1 (SOD1) and glutathione peroxidase 1 (GPX1) was measured by RT-qPCR. " $\mathrm{P}<0.05$ compared with untreated cells; * $\mathrm{P}<0.05$ compared with cells exposed to $\mathrm{MG}(300 \mu \mathrm{M})$ alone.

MG-exposed cells. We found also that the expression of GPX increased significantly in the MG-exposed cells compared to the control cells (Fig. 4C). Pre-treatment of the RIN-m5F $\beta$-cells with deoxyactein $(0.1 \mu \mathrm{M})$ further increased the gene expression of GPX compared to the MG-exposed cells. These 

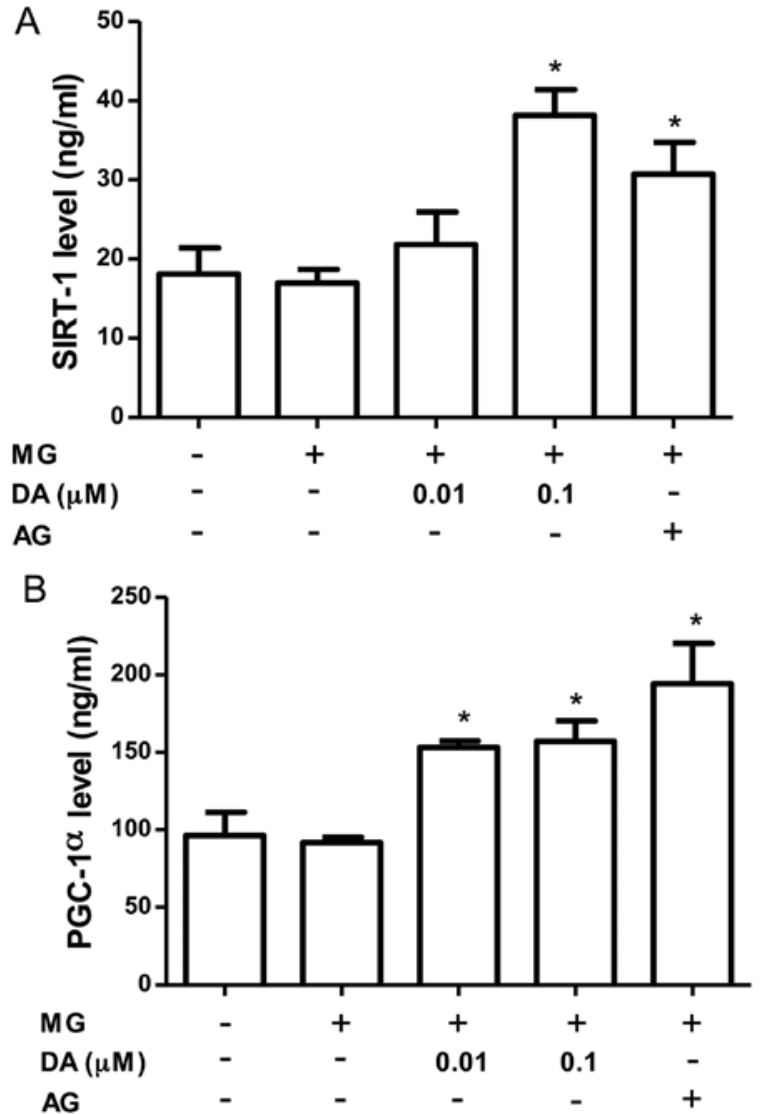

Figure 5. Effect of deoxyactein (DA) on the levels of (A) sirtuin 1 (SIRT1) and (B) peroxisome proliferator-activated receptor- $\gamma$ coactivator- $1 \alpha$ (PGC-1 $\alpha)$ in methylglyoxal (MG)-exposed cells. The RIN-m5F cells were incubated with DA or $400 \mu \mathrm{M}$ aminoguanidine (AG) prior to exposure to $300 \mu \mathrm{M}$ MG for $48 \mathrm{~h}$. The control values for SIRT1 and PGC-1 $\alpha$ were $18.1 \pm 3.3$ and $96.3 \pm 14.98 \mathrm{ng} / \mathrm{mg}$, respectively. ${ }^{\text {}} \mathrm{P}<0.05$ compared with untreated cells; ${ }^{*} \mathrm{P}<0.05$ compared with cells exposed to $\mathrm{MG}(300 \mu \mathrm{M})$ alone.

findings suggest that deoxyactein is capable of enhancing the antioxidant status by upregulating the mRNA expression of SOD and GPX in MG-exposed RIN-M5F $\beta$-cells.

Effects of deoxyactein on mitochondrial metabolic factors in MG-exposed RIN-M5F cells. SIRT1 likely regulates multiple pathways involved in mitochondrial biogenesis. As shown in Fig. 5A, the SIRT-1 levels were increased by treatment with deoxyactein $(0.1 \mu \mathrm{M})$ or AG. PGC- $1 \alpha$ is also considered to be a key regulator of mitochondrial biogenesis in multiple tissues (31). Since SIRT1 may also directly deacetylate PGC-1 $\alpha$ and increase its activity (32), we measured the PGC-1 $\alpha$ levels in the pancreatic $\beta$-cells. As shown in Fig. 5B, the level of PGC- $1 \alpha$ was significantly increased by deoxyactein $(0.01-0.1 \mu \mathrm{M})$ or AG treatment. These data indicate that deoxyactein enhances pancreatic $\beta$-cell function due to the activation of the SIRT1-PGC-1 $\alpha$ pathway. MG alone did not affect SIRT1 and PGC-1 $\alpha$ protein expression. This may be due to compensatory mechanisms maintaining the levels of these proteins.

Inhibitory effect of deoxyactein on MG-induced glycation in RIN-m5F cells. MG reacts with free amino groups and thiols to form AGE protein adducts, thereby altering protein function (33). Thus, we investigated whether the incubation
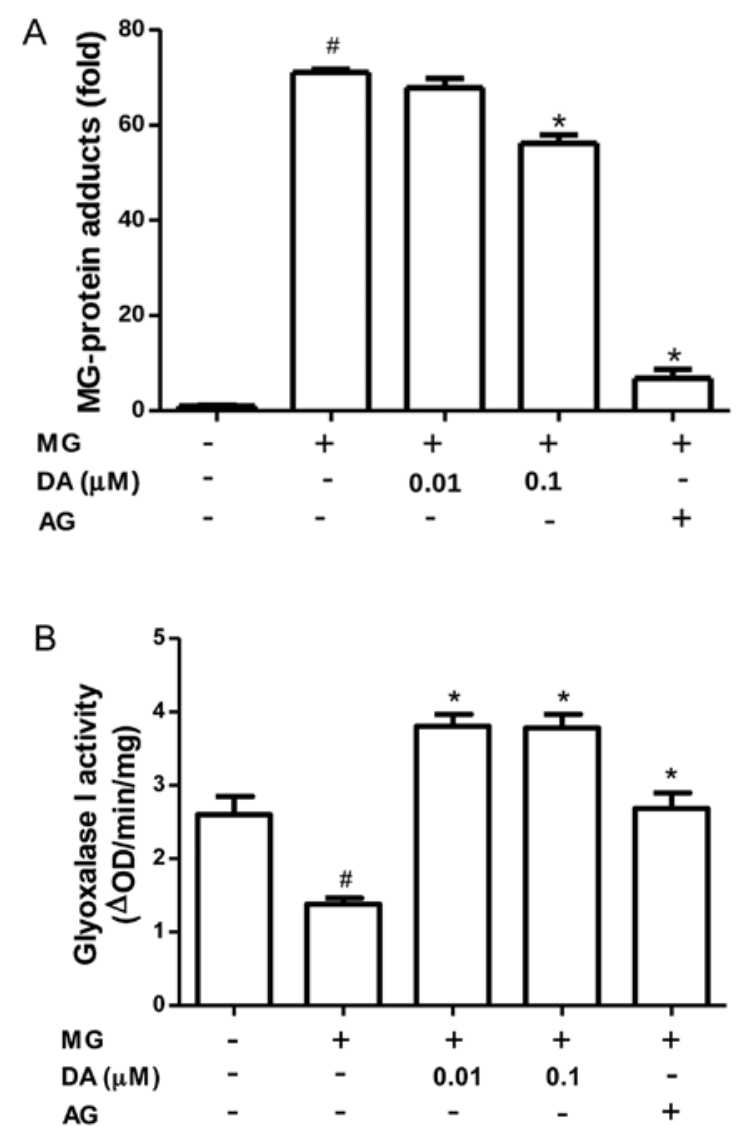

Figure 6. Effect of deoxyactein (DA) on (A) methylglyoxal (MG)-induced protein adduct formation and (B) glyoxalase I activity in MG-exposed cells. The RIN-m5F cells were incubated with DA or $400 \mu \mathrm{M}$ aminoguanidine (AG) prior to exposure to $300 \mu \mathrm{M} \mathrm{MG}$ for $48 \mathrm{~h}$. The control values for protein adduct formation and glyoxalase I activity were $2.603 \pm 0.348$ and $0.013 \pm 0.001$ $\Delta \mathrm{OD} / \mathrm{min} / \mathrm{mg}$, respectively. ${ }^{\#} \mathrm{P}<0.05$ compared with untreated cells; ${ }^{*} \mathrm{P}<0.05$ compared with cells exposed to $\mathrm{MG}(300 \mu \mathrm{M})$ alone.

of RIN-m5F $\beta$-cells with deoxyactein could reduce the formation of protein adducts. As shown in Fig. 6A, protein adducts accumulated in the cells exposed to $300 \mu \mathrm{M}$ MG. However, pre-treatment with deoxyactein $(0.1 \mu \mathrm{M})$ or AG decreased protein adduct formation induced by MG. These data indicated that deoxyactein blocked the MG-derived protein glycation in RIN-m5F $\beta$-cells, which may be part of the mechanisms responsible for its inhibitory effecs on RIN-M5F $\beta$-cell death. MG is detoxified by the glyoxalase system. Thus, we examined the effect of deoxyactein on the activity of glyoxalase I in RIN-m5F $\beta$-cells. As shown in Fig. 6B, we found a significant decrease in the glyoxalase I activity of RIN-m5F $\beta$-cells exposed to $\mathrm{MG}(300 \mu \mathrm{M})$. However, deoxyactein $(0.01-0.1 \mu \mathrm{M})$ or $\mathrm{AG}$ recovered the glyoxalase I activity inhibited by MG. These data demonstrate that deoxyactein decreases MG-induced glycation in part through an increase in glyoxalase I activity.

\section{Discussion}

Pancreatic $\beta$-cell dysfunction is the pivotal physiological disorder in the development of diabetes. Decreased viability of and damage to $\beta$-cells accelerates diabetic pathogenesis, which is associated with an increased risk of mortality. In the present study, we investigated the effects of deoxyactein on pancreatic 
$\beta$-cells under MG-induced toxic conditions and the underlying mechanisms. The results revealed that a decrease in cell viability was detected when the MG concentration exceeded $300 \mu \mathrm{M}$. When the cells were pre-treated with deoxyactein, pancreatic $\beta$-cell toxicity was attenuated. This study indicated that incubation with $300 \mu \mathrm{M}$ MG for $48 \mathrm{~h}$ significantly impaired insulin secretion and the expression of the insulin gene in RIN-m5F cells. In addition to insulin secretion, insulin gene transcription is a pancreatic $\beta$-cell-specific function, and inappropriate insulin biosynthesis may contribute to the pathogenesis of diabetes mellitus (34). Previous studies have shown that MG alters insulin secretion $(21,35)$. The present study on pancreatic $\beta$-cells further documents the inhibitory effect of MG on insulin secretion. Moreover, pre-treatment with deoxyactein caused a significant increase in insulin secretion and gene expression under conditions of MG-induced toxicity. Among several transcription factors binding to the promoter of the insulin gene, PDX-1 has been shown to be important for the maintenance of insulin biosynthesis, as well as $\beta$-cell mass (36). Mice homozygous for a targeted disruption of the PDX-1 gene fail to develop a pancreas, and the inactivation of PDX-1 specifically in $\beta$-cells of mice decreases $\beta$-cell mass and insulin expression (36). It has been shown that insulin stimulates PDX-1 binding to the insulin promoter via PI3K and SAPK2/p38 (37). PDX-1 deficiency contributes to impaired proliferation and enhanced apoptosis via transcriptional mechanisms in models of type 2 diabetes (38). In this study, PDX-1 gene expression was significantly increased by treatment with deoxyactein. Therefore, it may be presumed that deoxyactein may attenuate the inhibitory effect of $\mathrm{MG}$ on insulin secretion by regulating insulin and PDX-1 gene expression.

In response to acute elevation of glucose and survival factors, such as insulin, PDX-1 is phosphorylated and translocates to the nucleus (39). By contrast, stimuli associated with diabetes, such as oxidative stress (40) and free fatty acids (41), cause nuclear exclusion of PDX-1 (41). Ardestani et al (42) showed that the nuclear localization of PDX-1 is essential for functional $\beta$-cells, which is a novel mechanism of the protective effects of IL-1 receptor antagonist in $\beta$-cell survival and function.

Treatment with an IL-1 $\beta$ antibody also improves glycemic control in diet-induced obesity in mice (43). IL-1 $\beta$ is thought to be a critical mediator of the impaired function of pancreatic $\beta$-cells during the development of autoimmune type 1 diabetes (44). Furthermore, previous findings have established the role of IL-1 $\beta$ in $\beta$-cell failure in type 2 diabetes (45). The IL-1 $\beta$-induced dysfunction of the pancreatic $\beta$-cells is mainly due to the activation of extracellular signal-regulated kinase (ERK) and nuclear factor- $\kappa \mathrm{B}(45)$. The exposure of pancreatic islets to IL-1 $\beta$ decreases the mRNA levels of proinsulin-converting enzymes, indicating a decreased pro-insulin conversion (46). In this study, we demonstrated a profound inhibitory effect of deoxyactein on MG-induced IL- $1 \beta$ production by $\beta$-cells. The protective action toward pancreatic $\beta$-cell function and viability by deoxyactein is likely due to its inhibition of IL-1 $\beta$. Therefore, the present study shows that deoxyactein may protect pancreatic islets against the noxious effects induced by IL-1 $\beta$.

MG accumulates in oxidative conditions and may contribute to oxidant-induced cellular damage (47). Increased MG modification of proteins is a likely outcome of oxidative stress, and increased MG modification of mitochondrial proteins may also induce oxidative stress (48). Furthermore, oxidative stress has been implicated in the deterioration of insulin signaling in diabetes (49), in decreased insulin secretion and in $\beta$-cell death (50). In this study, to evaluate the role of free radicals in the protective activity of deoxyactein, its effect on MG-induced ROS generation was analyzed using $\mathrm{H}_{2}$ DCFDA assays. Following pre-treatment with deoxyactein, MG-induced ROS generation was observed to decline, which may account for the observed cytoprotective effects of deoxyactein. The increased generation of ROS accelerates the oxidation of lipids, proteins, nucleic acids and other molecules. Mitochondrial cardiolipin molecules are an early target of ROS attack, either due to their high content of unsaturated fatty acids or because of their location in the inner mitochondrial membrane near the site of ROS production (51). It seems likely that enhanced ROS production could lead to cardiolipin oxidative damage, which would negatively impact the biochemical function of the mitochondrial membranes, altering membrane fluidity and ion permeability. In deoxyactein-pre-treated cells, MG-induced cardiolipin peroxidation was significantly decreased. The inhibitory effect of deoxyactein on cardiolipin peroxidation in the mitochondria can be explained by its ability to inhibit the peroxidation of linoleic fatty acid constituents of mitochondrial cardiolipin molecules. These data strongly indicate that deoxyactein modulates ROS generation via the reduction of $\mathrm{MG}$-induced mitochondrial membrane lipid peroxidation.

Overabundant ROS are scavenged by endogenous antioxidant enzymes. In cells, SOD catalyzes the conversion of superoxide to hydrogen peroxide, which is further reduced to $\mathrm{H}_{2} \mathrm{O}$ by the activity of CAT or GPX. In the present study, MG significantly decreased the expression of SOD and increased that of GPX in pancreatic $\beta$-cells. Antioxidant defenses are affected by oxidative challenge, evoking a marked increase in GPX activity to cope with elevated ROS. The induction of GPX is an essential mechanism of the cell defense against oxidative insults and consequently plays a major role in overcoming ROS production (52). In the study, pre-treatment with deoxyactein increased the gene expression of these antioxidant enzymes in MG-exposed pancreatic $\beta$-cells, indicating that deoxyactein is able to reduce MG-induced oxidative stress. This finding should be relevant to therapies directed toward pancreatic $\beta$-cells due to the low antioxidant enzyme gene expression in pancreatic tissue compared to other tissues (53). Our results mentioned above indicate that the treatment of pancreatic $\beta$-cells with deoxyactein creates conditions favorable for combating the increased generation of ROS induced by MG, and consequently the maintenance of cell function and viability. Muscogiuri et al (54) reported that the genetic ablation of SOD caused glucose intolerance, which was associated with reduced in vivo insulin secretion by pancreatic $\beta$-cells and decreased $\beta$-cell volume, which suggests that oxidative stress caused by SOD ablation leads to glucose intolerance secondary to $\beta$-cell dysfunction. Studies have reported that the overexpression of SOD provides a protective effect to insulin-secreting cells (55) and against streptozotocin-induced diabetes (56). In addition, the overexpression of GPX has been shown to confer a protective effect against ROS-induced oxidative stress by increasing the activity of SOD (57). Therefore, the deoxyactein-induced increase in the activities of GPX and SOD, which participate 
in the defense against hydrogen peroxides and superoxides, is essential to prevent ROS cytotoxicity induced by MG.

The main source of ROS in diabetes is most probably altered mitochondrial metabolism, which results in the overproduction of superoxide by the electron transport chain (58). The transcriptional co-activator, PGC- $1 \alpha$, and the $\mathrm{NAD}^{+}$-dependent deacetylase, SIRT1, are considered important inducers of mitochondrial biogenesis as they regulate the transcription of nucleus-encoded mitochondrial genes (59). SIRT1 acts as an important regulator of metabolism by controlling the activity of key transcription factors, such as PGC-1 $\alpha$, forkhead box protein $\mathrm{O} 1$ (FOXO1) and p53 $(60,61)$. PGC-1 $\alpha$ functions as an upstream inducer of genes of mitochondrial metabolism by positively affecting the activity of some hormone nuclear receptors and nuclear transcription factors (e.g., NRF-1 and -2) (62). Additionally, NRF-1 regulates the activation of the Tfam, Tfb1m and Tfb $2 \mathrm{~m}$ promoters and indirectly affects the expression of Cox genes, Glut4 and PGC-1 $\alpha$ itself (63). Our data revealed that deoxyactein increased the levels of SIRT1 and PGC-1 $\alpha$. Therefore, the beneficial effect of deoxyactein is mediated by enhanced mitochondrial biogenesis via the activation of the SIRT1-PGC-1 $\alpha$ pathway.

The MG-induced formation of protein adducts with cell surface or intracellular targets has been shown to initiate tyrosine kinase signaling (64), mitochondrial dysfunction (65) and the activation of the caspase cascade (66). MG-protein adducts are generated by irreversible nonenzymatic modification of free amino groups of proteins, and carbonyl stress results from an imbalance between reactive carbonyl species levels, the efficiency of scavenger and detoxification pathways, and accumulation of MG-protein adducts (67). The modification of proteins and DNA by MG has emerged as an important endogenous threat to the functional integrity of the proteome and genome. Moreover, the crosslinking reaction that occurs during MG amino acid glycation has been shown to yield the superoxide radical anion (68). Protein modification by MG is directed to functional sites where it is associated with metabolic, structural and functional abnormalities: for example, mitochondrial dysfunction with increased formation of ROS (66), cell detachment from the extracellular matrix by decreased integrin binding to MG-modified extracellular matrix proteins and anoikis (69), and the induction of accelerated cell senescence (70). In the present study, the exposure of pancreatic $\beta$-cells to MG increased the formation of protein adducts to levels above those observed in the controls. However, pretreatment of the MG-exposed cells with $0.1 \mu \mathrm{M}$ deoxyactein decreased the formation of protein adducts significantly. The present data indicate that deoxyactein may block MG-derived protein adduct formation in pancreatic $\beta$-cells, which may be involved in the mechanism protecting them against cell death. Therefore, deoxyactein may help prevent the development of diabetic complications by blocking the MG-mediated intracellular glycation system.

Under physiological conditions the glyoxalase system, in which the enzyme glyoxalase I is the rate-limiting step, efficiently detoxifies highly reactive carbonyls and the AGE precursor MG to D-lactate and thereby inhibits the formation of AGEs (5). We demonstrated that the activity of glyoxalase I was markedly increased by deoxyactein under conditions of MG-induced toxicity. Glyoxalase I is ubiquitously distributed in cells and plays an important role in the regulation of signals related to oxidative stress and AGE formation (71). The overexpression of glyoxalase I inhibits intracellular AGE formation in bovine endothelial cells and prevents hyperglycemia-induced increases in macromolecular endocytosis (72). By contrast, glyoxalase I deficiency is associated with increased levels of AGEs (73). The overexpression of glyoxalase I exerts protective effects in renal ischemia-reperfusion injury via the reduction of MG accumulation in tubular cells (74). As excessive ROS production has been implicated in the pathogenesis of diabetes (75), pharmacologic agents that increase glyoxalase activity may have unique clinical efficacy in the prevention and treatment of these conditions. In this study, we demonstrated that deoxyactein significantly prevented the damage to pancreatic $\beta$-cell function induced by $\mathrm{MG}$, by preventing oxidative stress or enhancing the MG-detoxifying system. Therefore, deoxyactein may be employed to protect against diseases, such as diabetes, in which excess the production of ROS has been implicated as a causal or contributory factor.

In conclusion, the present study indicates that MG negatively affects $\beta$-cell function, and that deoxyactein may ameliorate MG-induced pancreatic $\beta$-cell damage. The mechanisms of of action of deoxyactein likely involve the potentiation of SIRT-1/ PGC-1 $\alpha$ signaling, the increased activity of glyoxalase I, the elevated gene expression of PDX-1, INS2, SOD and GPX and protection against detrimental oxidative and inflammatory damage. Deoxyactein may allow the preservation and/or improvement of $\beta$-cell function in diabetics associated with elevated circulating levels of toxic aldehydes due to chronic hyperglycemia.

\section{Acknowledgements}

This study was supported by a grant from the Korea Health Technology R\&D Project through the Korea Helath Industry Development Institute (KHIDI), funded by the Ministry of Health and Welfare, Republic of Korea (grant no. HI14C-2700-020014) and by the Basic Science Research Program through the National Research Foundation of Korea (NRF) funded by the Ministry of Education (no. NRF-2013R1A1A2A10004361).

\section{References}

1. Brownlee M: The pathobiology of diabetic complications: A unifying mechanism. Diabetes 54: 1615-1625, 2005.

2. Kalapos MP: The tandem of free radicals and methylglyoxal. Chem Biol Interact 171: 251-271, 2008.

3. Wu CH, Huang SM, Lin JA and Yen GC: Inhibition of advanced glycation endproduct formation by foodstuffs. Food Funct 2: 224-234, 2011.

4. Shu T, Zhu Y, Wang H, Lin Y, Ma Z and Han X: AGEs decrease insulin synthesis in pancreatic $\beta$-cell by repressing $\mathrm{Pdx}-1$ protein expression at the post-translational level. PLoS One 6: e18782, 2011.

5. Thornalley PJ: Glyoxalase I - structure, function and a critical role in the enzymatic defence against glycation. Biochem Soc Trans 31: 1343-1348, 2003.

6. Solomon TPJ, Knudsen SH, Karstoft K, Winding K, Holst JJ and Pedersen BK: Examining the effects of hyperglycemia on pancreatic endocrine function in humans: Evidence for in vivo glucotoxicity. J Clin Endocrinol Metab 97: 4682-4691, 2012.

7. Brownlee M: A radical explanation for glucose-induced beta cell dysfunction. J Clin Invest 112: 1788-1790, 2003.

8. Sakuraba H, Mizukami H, Yagihashi N, Wada R, Hanyu C and Yagihashi S: Reduced beta-cell mass and expression of oxidative stress-related DNA damage in the islet of Japanese Type II diabetic patients. Diabetologia 45: 85-96, 2002. 
9. Tanaka Y, Tran PO, Harmon J and Robertson RP: A role for glutathione peroxidase in protecting pancreatic beta cells against oxidative stress in a model of glucose toxicity. Proc Natl Acad Sci USA 99: 12363-12368, 2002.

10. Welsh N, Margulis B, Borg LA, Wiklund HJ, Saldeen J, Flodström M, Mello MA, Andersson A, Pipeleers DG, Hellerström C, et al: Differences in the expression of heat-shock proteins and antioxidant enzymes between human and rodent pancreatic islets: Implications for the pathogenesis of insulindependent diabetes mellitus. Mol Med 1: 806-820, 1995.

11. Bonora E: Protection of pancreatic beta-cells: Is it feasible? Nutr Metab Cardiovasc Dis 18: 74-83, 2008.

12. Chang-Chen KJ, Mullur R and Bernal-Mizrachi E: Beta-cell failure as a complication of diabetes. Rev Endocr Metab Disord 9 : 329-343, 2008.

13. Philippe J and Raccah D: Treating type 2 diabetes: How safe are current therapeutic agents? Int J Clin Pract 63: 321-332, 2009.

14. Lee SH, Park MH, Park SJ, Kim J, Kim YT, Oh MC, Jeong Y Kim M, Han JS and Jeon YJ: Bioactive compounds extracted from Ecklonia cava by using enzymatic hydrolysis protects high glucose-induced damage in INS-1 pancreatic $\beta$-cells. Appl Biochem Biotechnol 167: 1973-1985, 2012.

15. Chakraborty D, Samadder A, Dutta S and Khuda-Bukhsh AR: Antihyperglycemic potentials of a threatened plant, Helonias dioica: Antioxidative stress responses and the signaling cascade. Exp Biol Med (Maywood) 237: 64-76, 2012.

16. Hanhineva K, Törrönen R, Bondia-Pons I, Pekkinen J, Kolehmainen M, Mykkänen $\mathrm{H}$ and Poutanen $\mathrm{K}$ : Impact of dietary polyphenols on carbohydrate metabolism. Int J Mol Sci 11: 1365-1402, 2010.

17. Babu PV, Liu D and Gilbert ER: Recent advances in understanding the anti-diabetic actions of dietary flavonoids. J Nutr Biochem 24: 1777-1789, 2013.

18. McKenna DJ, Jones K, Humphrey S and Hughes K: Black cohosh: Efficacy, safety, and use in clinical and preclinical applications. Altern Ther Health Med 7: 93-100, 2001.

19. Choi EM: Deoxyactein isolated from Cimicifuga racemosa protects osteoblastic MC3T3-E1 cells against antimycin A-induced cytotoxicity. J Appl Toxicol 33: 488-494, 2013.

20. Choi EM: Deoxyactein stimulates osteoblast function and inhibits bone-resorbing mediators in MC3T3-E1 cells. J Appl Toxicol 33: 190-195, 2013.

21. Sheader EA, Benson RS and Best L: Cytotoxic action of methylglyoxal on insulin-secreting cells. Biochem Pharmacol 61: 1381-1386, 2001.

22. Tiedge M, Lortz S, Munday R and Lenzen S: Complementary action of antioxidant enzymes in the protection of bioengineered insulin-producing RINm5F cells against the toxicity of reactive oxygen species. Diabetes 47: 1578-1585, 1998.

23. Jakubowski W and Bartosz G: 2,7-dichlorofluorescin oxidation and reactive oxygen species: What does it measure? Cell Biol Int 24: 757-760, 2000.

24. Thornalley PJ and Tisdale MJ: Inhibition of proliferation of human promyelocytic leukaemia HL60 cells by S-D-lactoylglutathione in vitro. Leuk Res 12: 897-904, 1988.

25. Rains JL and Jain SK: Oxidative stress, insulin signaling, and diabetes. Free Radic Biol Med 50: 567-575, 2011.

26. Suh KS, Rhee SY, Kim YS and Choi EM: Inhibitory effect of apocynin on methylglyoxal-mediated glycation in osteoblastic MC3T3-E1 cells. J Appl Toxicol 35: 350-357, 2015.

27. Vulesevic B, McNeill B, Giacco F, Maeda K, Blackburn NJ, Brownlee M, Milne RW and Suuronen EJ: Methylglyoxal-induced endothelial cell loss and inflammation contribute to the development of diabetic cardiomyopathy. Diabetes 65: 1699-1713, 2016.

28. Sun YP, Gu JF, Tan XB, Wang CF, Jia XB, Feng L and Liu JP: Curcumin inhibits advanced glycation end product-induced oxidative stress and inflammatory responses in endothelial cell damage via trapping methylglyoxal. Mol Med Rep 13: 1475-1486, 2016.

29. Gogvadze V, Orrenius S, and Zhivotovsky B: Multiple pathways of cytochrome c release from mitochondria in apoptosis. Biochim Biophys Acta 1757: 639-647, 2006.

30. Petit JM, Maftah A, Ratinaud MH and Julien R: 10N-nonyl acridine orange interacts with cardiolipin and allows the quantification of this phospholipid in isolated mitochondria. Eur $\mathbf{J}$ Biochem 209: 267-273, 1992.

31. Jornayvaz FR and Shulman GI: Regulation of mitochondrial biogenesis. Essays Biochem 47: 69-84, 2010.

32. Nemoto S, Fergusson MM and Finkel T: SIRT1 functionally interacts with the metabolic regulator and transcriptional coactivator PGC-1 \{alpha\}. J Biol Chem 280: 16456-16460, 2005
33. Salahuddin P, Rabbani G, and Khan RH: The role of advanced glycation end products in various types of neurodegenerative disease: a therapeutic approach. Cell Mol Biol Lett 19: 407-437, 2014.

34. Sherry NA, Tsai EB and Herold KC: Natural history of $\beta$-cell function in type 1 diabetes. Diabetes 54 (Suppl 2): S32-S39, 2005.

35. Dhar A, Dhar I, Jiang B, Desai KM and Wu L: Chronic methylglyoxal infusion by minipump causes pancreatic beta-cell dysfunction and induces type 2 diabetes in Sprague-Dawley rats. Diabetes 60: 899-908, 2011.

36. Ahlgren U, Jonsson J, Jonsson L, Simu K and Edlund H: betacell-specific inactivation of the mouse Ipf1/Pdx1 gene results in loss of the beta-cell phenotype and maturity onset diabetes. Genes Dev 12: 1763-1768, 1998.

37. Wu H, MacFarlane WM, Tadayyon M, Arch JR, James RF and Docherty K: Insulin stimulates pancreatic-duodenal homoeobox factor-1 (PDX1) DNA-binding activity and insulin promoter activity in pancreatic beta cells. Biochem J 344: 813-818, 1999.

38. Leibowitz G, Ferber S, Apelqvist A, Edlund H, Gross DJ, Cerasi E, Melloul D and Kaiser N: IPF1/PDX1 deficiency and beta-cell dysfunction in Psammomys obesus, an animal With type 2 diabetes. Diabetes 50: 1799-1806, 2001.

39. Macfarlane WM, Shepherd RM, Cosgrove KE, James RF, Dunne MJ and Docherty K: Glucose modulation of insulin mRNA levels is dependent on transcription factor PDX-1 and occurs independently of changes in intracellular $\mathrm{Ca}^{2+}$. Diabetes 49: 418-423, 2000.

40. Kawamori D, Kaneto H, Nakatani Y,Matsuoka TA, Matsuhisa M, Hori $\mathrm{M}$ and Yamasaki Y: The forkhead transcription factor Foxol bridges the JNK pathway and the transcription factor PDX-1 through its intracellular translocation. J Biol Chem 281: 1091-1098, 2006

41. Hagman DK, Hays LB, Parazzoli SD and Poitout V: Palmitate inhibits insulin gene expression by altering PDX-1 nuclear localization and reducing MafA expression in isolated rat islets of Langerhans. J Biol Chem 280: 32413-32418, 2005.

42. Ardestani A, Sauter NS, Paroni F, Dharmadhikari G, Cho JH, Lupi R, Marchetti P, Oberholzer J, Conte JK and Maedler K: Neutralizing interleukin-1beta (IL-1beta) induces beta-cell survival by maintaining PDX1 protein nuclear localization. J Biol Chem 286: 17144-17155, 2011.

43. Osborn O, Brownell SE, Sanchez-Alavez M, Salomon D, Gram H and Bartfai T: Treatment with an Interleukin 1 beta antibody improves glycemic control in diet-induced obesity. Cytokine 44: $141-148,2008$.

44. Mandrup-Poulsen T: The role of interleukin-1 in the pathogenesis of IDDM. Diabetologia 39: 1005-1029, 1996.

45. Maedler K, Sergeev P, Ris F, Oberholzer J, Joller-Jemelka HI, Spinas GA, Kaiser N, Halban PA and Donath MY: Glucose-induced beta cell production of IL-1beta contributes to glucotoxicity in human pancreatic islets. J Clin Invest 110: 851-860, 2002.

46. Börjesson A and Carlsson C: Altered proinsulin conversion in rat pancreatic islets exposed long-term to various glucose concentrations or interleukin-1beta. J Endocrinol 192: 381-387, 2007.

47. Abordo EA, Minhas HS and Thornalley PJ: Accumulation of alpha-oxoaldehydes during oxidative stress: A role in cytotoxicity. Biochem Pharmacol 58: 641-648, 1999.

48. Miyazawa N, Abe M, Souma T, Tanemoto M,Abe T, Nakayama M and Ito S: Methylglyoxal augments intracellular oxidative stress in human aortic endothelial cells. Free Radic Res 44: 101-107, 2010.

49. Newsholme P, Haber EP, Hirabara SM, Rebelato EL, Procopio J, Morgan D, Oliveira-Emilio HC, Carpinelli AR and Curi R: Diabetes associated cell stress and dysfunction: Role of mitochondrial and non-mitochondrial ROS production and activity. J Physiol 583: 9-24, 2007

50. Robertson RP: Chronic oxidative stress as a central mechanism for glucose toxicity in pancreatic islet beta cells in diabetes. J Biol Chem 279: 42351-42354, 2004.

51. Petrosillo G, Di Venosa N, Pistolese M, Casanova G, Tiravanti E, Colantuono G, Federici A, Paradies G and Ruggiero FM: Protective effect of melatonin against mitochondrial dysfunction associated with cardiac ischemia-reperfusion: Role of cardiolipin. FASEB J 20: 269-276, 2006.

52. Martín MA, Serrano AB, Ramos S, Pulido MI, Bravo L and Goya L: Cocoa flavonoids up-regulate antioxidant enzyme activity via the ERK1/2 pathway to protect against oxidative stress-induced apoptosis in HepG2 cells. J Nutr Biochem 21: 196-205, 2010.

53. Robertson RP and Harmon JS: Pancreatic islet beta-cell and oxidative stress: The importance of glutathione peroxidase. FEBS Lett 581: 3743-3748, 2007 
54. Muscogiuri G, Salmon AB, Aguayo-Mazzucato C, Li M, Balas B, Guardado-Mendoza R, Giaccari A, Reddick RL, Reyna SM, Weir G, et al: Genetic disruption of SOD1 gene causes glucose intolerance and impairs $\beta$-cell function. Diabetes 62: 4201-4207, 2013.

55. Moriscot C, Pattou F, Kerr-Conte J, Richard MJ, Lemarchand P and Benhamou PY: Contribution of adenoviral-mediated superoxide dismutase gene transfer to the reduction in nitric oxide-induced cytotoxicity on human islets and INS-1 insulinsecreting cells. Diabetologia 43: 625-631, 2000.

56. Kubisch HM, Wang J, Bray TM and Phillips JP: Targeted overexpression of $\mathrm{Cu} / \mathrm{Zn}$ superoxide dismutase protects pancreatic beta-cells against oxidative stress. Diabetes 46: 1563-1566, 1997.

57. Mysore TB, Shinkel TA, Collins J, Salvaris EJ, Fisicaro N, Murray-Segal LJ, Johnson LE, Lepore DA, Walters SN, Stokes R, et al: Overexpression of glutathione peroxidase with two isoforms of superoxide dismutase protects mouse islets from oxidative injury and improves islet graft function. Diabetes 54: 2109-2116, 2005.

58. Nishikawa T, Edelstein D, Du XL, Yamagishi S, Matsumura T, Kaneda Y, Yorek MA, Beebe D, Oates PJ, Hammes HP, et al: Normalizing mitochondrial superoxide production blocks three pathways of hyperglycaemic damage. Nature 404: 787-790, 2000.

59. Rodgers JT, Lerin C, Gerhart-Hines Z and Puigserver P Metabolic adaptations through the PGC-1 alpha and SIRT1 pathways. FEBS Lett 582: 46-53, 2008

60. Cheng HL, Mostoslavsky R, Saito S, Manis JP, Gu Y, Patel P Bronson R, Appella E, Alt FW and Chua KF: Developmental defects and p53 hyperacetylation in Sir2 homolog (SIRT1) deficient mice. Proc Natl Acad Sci USA 100: 10794-10799, 2003.

61. Brunet A, Sweeney LB, Sturgill JF, Chua KF, Greer PL, Lin Y, Tran H, Ross SE, Mostoslavsky R, Cohen HY, et al: Stressdependent regulation of FOXO transcription factors by the SIRT1 deacetylase. Science 303: 2011-2015, 2004.

62. Finkel T: Cell biology: A clean energy programme. Nature 444: $151-152,2006$

63. Hock MB and Kralli A: Transcriptional control of mitochondrial biogenesis and function. Annu Rev Physiol 71: 177-203, 2009.

64. Akhand AA, Kato M, Suzuki H, Liu W, Du J, Hamaguchi M, Miyata T, Kurokawa K and Nakashima I: Carbonyl compounds cross-link cellular proteins and activate protein-tyrosine kinase p60c-Src. J Cell Biochem 72: 1-7, 1999.

65. Rosca MG, Monnier VM, Szweda LI and Weiss MF: Alterations in renal mitochondrial respiration in response to the reactive oxoaldehyde methylglyoxal. Am J Physiol Renal Physiol 283: F52-F59, 2002.
66. Akhand AA, Hossain K, Mitsui H, Kato M, Miyata T, Inagi R, Du J, Takeda K, Kawamoto Y, Suzuki H, et al: Glyoxal and methylglyoxal trigger distinct signals for map family kinases and caspase activation in human endothelial cells. Free Radic Biol Med 31: 20-30, 2001.

67. Stitt AW, Jenkins AJ and Cooper ME: Advanced glycation end products and diabetic complications. Expert Opin Investig Drugs 11: 1205-1223, 2002

68. Yim HS, Kang SO, Hah YC, Chock PB and Yim MB: Free radicals generated during the glycation reaction of amino acids by methylglyoxal. A model study of protein-cross-linked free radicals. J Biol Chem 270: 28228-28233, 1995.

69. Pedchenko VK, Chetyrkin SV, Chuang P, Ham AJ, Saleem MA, Mathieson PW, Hudson BG and Voziyan PA: Mechanism of perturbation of integrin-mediated cell-matrix interactions by reactive carbonyl compounds and its implication for pathogenesis of diabetic nephropathy. Diabetes 54: 2952-2960, 2005.

70. Sejersen $\mathrm{H}$ and Rattan SI: Dicarbonyl-induced accelerated aging in vitro in human skin fibroblasts. Biogerontology 10: 203-211,2009.

71. Barati MT, Merchant ML, Kain AB, Jevans AW, McLeish KR and Klein JB: Proteomic analysis defines altered cellular redox pathways and advanced glycation end-product metabolism in glomeruli of db/db diabetic mice. Am J Physiol Renal Physiol 293: F1157-F1165, 2007.

72. Shinohara M, Thornalley PJ, Giardino I, Beisswenger P, Thorpe SR, Onorato $\mathrm{J}$ and Brownlee M: Overexpression of glyoxalase-I in bovine endothelial cells inhibits intracellular advanced glycation endproduct formation and prevents hyperglycemia-induced increases in macromolecular endocytosis. J Clin Invest 101: 1142-1147, 1998.

73. Miyata T, van Ypersele de Strihou C, Imasawa T, Yoshino A, Ueda Y, Ogura H, Kominami K, Onogi H, Inagi R, Nangaku M, et al: Glyoxalase I deficiency is associated with an unusual level of advanced glycation end products in a hemodialysis patient. Kidney Int 60: 2351-2359, 2001.

74. Kumagai T, Nangaku M, Kojima I, Nagai R, Ingelfinger JR, Miyata T, Fujita T and Inagi R: Glyoxalase I overexpression ameliorates renal ischemia-reperfusion injury in rats. Am J Physiol Renal Physiol 296: F912-F921, 2009.

75. McLellan AC, Thornalley PJ, Benn J and Sonksen PH: Glyoxalase system in clinical diabetes mellitus and correlation with diabetic complications. Clin Sci (Lond) 87: 21-29, 1994. 